P

азвитие мекарственно-индуцированного васкулита

кожи на фоне мечения ингибитором ФНО- $\alpha$ этанерцептом

при ревматоилном артрите

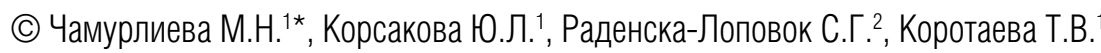

\author{
${ }^{1}$ Научно-исследовательский институт ревматологии им. В.А. Насоновой \\ 115522, Россия, г. Москва, Каширское шоссе, д. 34 А \\ 2 Первый МГМУ им. И.М. Сеченова Минздрава России \\ 119048, Россия, г. Москва, ул. Трубецкая, д. 8, стр. 2
}

Генно-инженерные биологические препараты (ГИБП) широко используются в терапии хронических воспалительных ревматологических заболеваний. Внедрение в клиническую практику таргетных ГИБП, в частности ингибиторов фрактора некроза опухоли альфа (и-ФНО- $\alpha$ ), изменило парадигму терапии ревматоидного артрита, значительно улучшило результаты лечения и исходы заболевания. Их эфрфективность доказана в рандомизированных клинических и наблюдательных исследованиях. Однако терапия и-ФНО- $\alpha$ может сопровождаться развитием нежелательных явлений как при краткосрочном, так и при длительном применении. Отмечается повышенный риск развития вирусных, бактериальных, грибковых, оппортунистических инфекций, туберкулеза, онкологических заболеваний, лимфом, кожных нежелательных явлений, например псориаза или васкулитов кожи. Представляем описание клинического случая возникновения лекарственно-индуцированного васкулита кожи на фроне лечения ревматоидного артрита и-ФНО- $\alpha$ этанерцептом.

Ключевые слова: васкулит кожи, этанерцепт, генно-инженерная терапия, клинический случай, ревматоидный артрит.

Конфликт интересов: авторы декларируют отсутствие явных и потенциальных конфликтов интересов, связанных с публикацией настоящей статьи.

Источник фринансирования: поисково-аналитическая работа проведена на личные средства авторского коллектива.

Согласие пациента: пациентка добровольно подписала информированное согласие на публикацию персональной медицинской информации в обезличенной форме (именно в этом журнале).

Для цитирования: Чамурлиева М.Н., Корсакова Ю.Л., Раденска-Лоповок С.Г., Коротаева Т.В. Развитие лекарственно-индуцированного васкулита кожи на фоне лечения ингибитором ФНО- $\alpha$ этанерцептом при ревматоидном артрите. Вестник дерматологии и венерологии. 2021;97(4):113-119.

doi: https://doi.org/10.25208/vdv1233 


\title{
Drug-induced cutaneous vasculitis developing during Etanercept treatment for rheumatoid arthritis
}

\author{
(C) Maria N. Chamurlieva ${ }^{1 *}$, Yulia L. Korsakova' ${ }^{1}$ Stefka G. Radenska-Lopovok², Tatiana V. Korotaeva ${ }^{1}$
}

\author{
1 V.A. Nasonova Scientific Research Institute of Rheumatology \\ Kashirskoe shosse, 34A, 115522, Moscow, Russia \\ ${ }^{2}$ Sechenov University \\ Trubetskaya str., 8, bldg 2, 119991, Moscow, Russia
}

Biological disease-modifying anti-rheumatic drugs (bDMARDs) are widely used for the treatment of chronic inflammatory rheumatic diseases. Since the introduction of tumor necrosis factor alpha (TNF- $\alpha$ ) inhibitors, the treatment of rheumatoid arthritis has been revolutionized. The approach of targeting TNF- $\alpha$ has considerably improved the success of the treatment of rheumatoid arthritis. Their effectiveness has been extensively proven in randomized clinical trials and in clinical practice. Randomized clinical trials and post-marketing studies proved that patients undergoing TNF- $\alpha$ inhibitors therapy are at increased risk of infectious disease, bacterial, viral, fungal, opportunistic, oncology and skin adverse effects such as psoriasis and angiitis of the skin. In this case report drug-induced cutaneous vasculitis developing during TNF- $\alpha$ inhibitor (Etanercept) treatment for rheumatoid arthritis is described.

Keywords: cutaneous vasculitis, Etanercept, biologic DMARDs, case report, rheumatoid arthritis.

Conflict of interest: the authors declare that there are no obvious and potential conflicts of interest associated with the publication of this article.

Source of funding: the work was done and published through financing at the place of work of the authors.

Patient consent: the patient voluntarily signed an informed consent for the publication of personal medical information in an impersonal form (in this particular journal).

For citation: Chamurlieva MN, Korsakova YuL, Radenska-Lopovok SG, Korotaeva TV. Drug-induced cutaneous vasculitis developing during Etanercept treatment for rheumatoid arthritis. Vestnik Dermatologii i Venerologii. 2021;97(4):113-119. doi: https://doi.org/10.25208/vdv1233 


\section{Актуальность}

Разработка и внедрение в клиническую практику ГИБП на основе моноклональных антител и рекомбинантных белков, ингибирующих активность важнейших провоспалительных цитокинов, патологическую активацию Т-лимфоцитов и В-лимфоцитов, значительно изменила парадигму терапии ревматоидного артрита - одного из наиболее тяжелых и прогрессирующих аутоиммунных ревматологических заболеваний [1].

За последние два десятилетия накоплен большой опыт применения ГИБП при ревматоидном артрите, в частности и-ФНО- $\alpha$. По данным метаанализов, посвященных безопасности этой группы лекарственных средств, наиболее часто регистрируются серьезные инфекции, туберкулез, оппортунистические инфекции, респираторные инфекции, парадоксальный псориаз, реже - лимфомы, рак кожи, другая онкологическая патология, неврологические, демиелинизирующие заболевания, системная красная волчанка, офтальмологическая патология, антифоссфолипидный синдром и повышение кардиоваскулярного риска [2-6]. В литературе имеются единичные наблюдения развития редкого нежелательного явления - васкулитов кожи на фоне терапии и-ФНО- $\alpha$ при ревматоидном артрите, воспалительных заболеваниях кишечника, псориатическом артрите и анкилозирующем спондилите. Точная диагностика этого нежелательного явления на фоне терапии ГИБП имеет большое практическое значение для выбора тактики лечения.

Среди и-ФНО- $\alpha$ этанерцепт является одним из широко применяющихся при ревматоидном артрите. Этанерцепт представляет собой гибридную молекулу, состоящую из ФНО-рецептора (Р) с молекулярной массой 75 kD, соединенную с Fc-фррагментом IgG1 человека [7].

Кроме перечисленных нежелательных явлений на фоне терапии этанерцептом у 5\% пациентов наблюдают развитие различных кожных васкулитов [8].

Кожные васкулиты - дерматозы, в клинической и патоморфологической картине которых первоначальным и ведущим звеном выступает неспецифическое воспаление стенок дермальных и гиподермальных кровеносных сосудов разного калибра [9].

Под нашим наблюдением находилась больная ревматоидным артритом, получавшая терапию этанерцептом, у которой развился лекарственно-индуцированный васкулит кожи.

\section{Описание случая}

Больная Н., 51 г., находилась на лечении в ФГБНУ НИИР им. В.А. Насоновой в феврале 2018 г. с диагнозом: ревматоидный артрит, серопозитивный, поздняя стадия, эрозивный (рентгенологическая стадия III) с системными проявлениями (ревматоидные узелки, лихорадка, гипотрофия мышц конечностей), активность высокая (DAS28 = 5,56), АЦЦП (+), ФК 3. За все время болезни пациентка находилась на терапии различными противоревматическими препаратами, включая такие ГИБП, как адалимумаб, ритуксимаб, тоцилизумаб, абатацепт, лечение которыми прекращалось либо в связи с развитием вторичной неэффективности, либо плохой переносимости или инфекции. В течение 2 лет проводилась терапия этанерцептом 50 мг/неделю. В конце этого периода терапии впервые появились высыпания розоватого цвета с изъязвлениями на коже в области верхних и нижних конечностей и ярко-красные болезненные мелкие образования в области ногтевых фраланг кистей. В течение наблюдения признаков туберкулезной инфекции не отмечалось, многократно проведенный диаскин-тест 1 раз в 6 месяцев - отрицательный.

Объективные данные: общее состояние удовлетворительное, на коже конечностей и ягодичной области наблюдаются розово-синюшные пятна, папулы с изъязвлениями, местами визуализируются некроз в центре высыпаний и единичные рубчики на месте их разрешений. В области ногтевых фаланг кистей визуализируются ярко-красные болезненные мелкие образования с появлением небольших узелков (рис. 1-3). Отмечается высокая воспалительная активность ревматоидного артрита (DAS28 = 5,56). По данным лабораторных исследований: ревматоидный фактор (РФ) - $621 \mathrm{ME} / \mathrm{Mл}$, антитела к циклическому цитруллинированному пептиду (АЦЦП) - 271,8 ед/мл, антинуклеарный фрактор $(\mathrm{AHФ)} \mathrm{-} \mathrm{0,5} \mathrm{опт.} \mathrm{ед} \mathrm{(норма} \mathrm{0,0-1,0),} \mathrm{антитела} \mathrm{к} \mathrm{двух-}$ спиральной ДНК (АТ к дс ДНК) - 4,6 МЕ/л (норма 0,0$100,0)$, антитела к протеиназе 3 (АТ к ПР-3) - 12,4 МЕ/л (норма - 0-20,0), антитела к миелопероксидазе (АТ к МПО) - 1,6 МЕ/л (норма 0,0-20,0), криоглобулины отрицательные. По данным иммунограммы: увеличение процентного и абсолютного количества В-клеток.

АНЦА-ассоциированные васкулиты и иммунокомплексные системные васкулиты в процессе обследования и наблюдения не были выявлены.

Гистологическое исследование кожного лоскута (из области бедра): в препаратах кожи отмечается умеренная вакуольная дистрофия клеток эпителия, местами с кариорексисом. В дерме имеют место рассеянные лимфоциты и множественные умеренно выраженные лимфогистиоцитарные инфильтраты периваскулярных пространств капилляров. Просвет капилляров

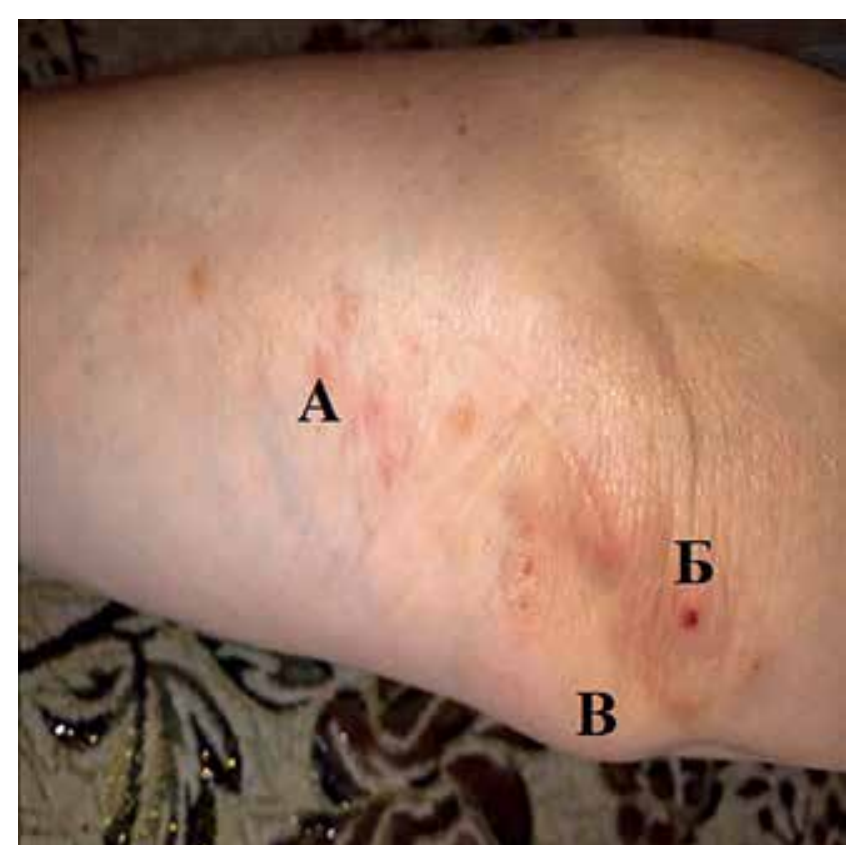

Рис. 1. А - плотные узелки на коже предплечья, Б - эрозии, В — ревма-
тоидный узелок
Fig. 1. A — dense nodules on the skin of the forearm, 5 — erosion. B — rheumatoid
nodule 


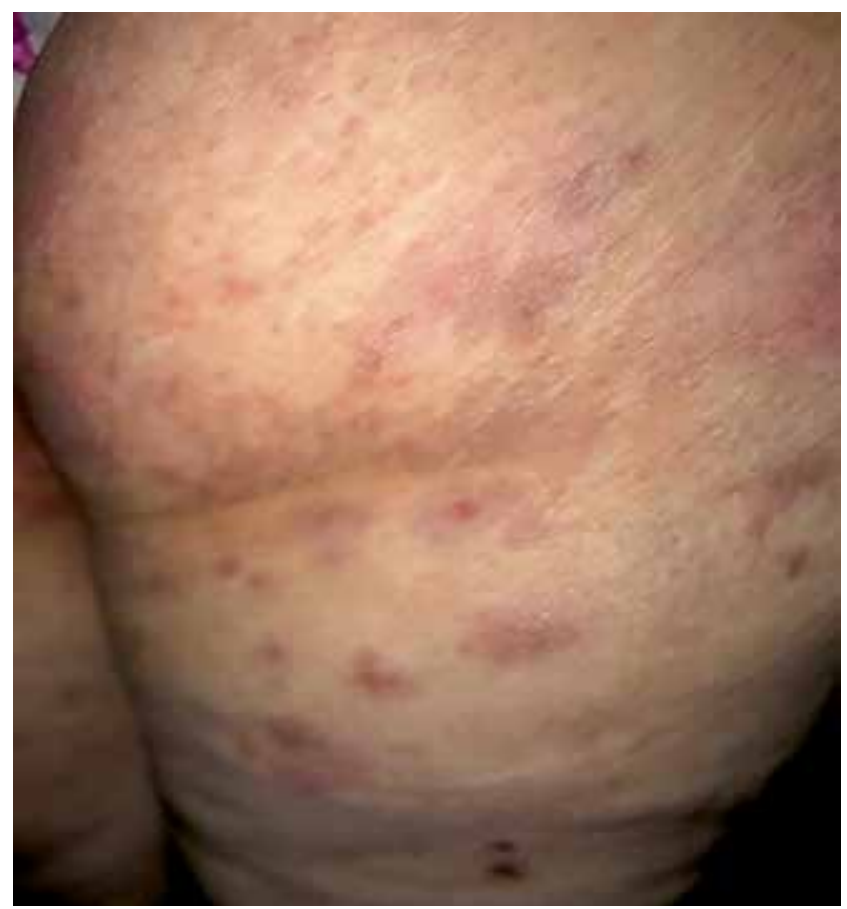

Рис. 2. Розово-синюшные пятна на коже нижних конечностей

Fig. 2. Pink-cyanotic spots on the skin of the lower limbs

не определяется в связи с набуханием и некрозом эндотелия и базальных мембран (рис. 4). В средней трети дермы - некроз стенок сосудов. Периваскулярные пространства, а также дерма отечны и инфильтрированы лимсооцитами и гистиоцитами (рис. 5).

Заключение: на основании выявленных морфологических изменений имеет место продуктивно-деструктивный васкулит кожи.

В кожном биоптате было выявлено выраженное воспаление дермы с поражением капиллярного русла в виде набухания и некроза. Данные изменения дермы и сосудов характеризуют их неспецифическое поражение. Описанные морфологические изменения укладываются в клинический диагноз «васкулит кожи». В связи с особенностями сосудистой сети в коже описанное заболевание называют в литературе разными терминами, которые рассматриваются как синонимы: дерматит, дерматоз, васкулит, васкулопатия.

Как дополнительный, но не обязательный критерий диагностики лекарственно-индуцированного васкулита кожи можно использовать иммунофрлюоресцентное выявление депозитов IgA1 в стенке кровеносных сосудов кожи. В крови могут выявляться аутоантитела к клеткам сосудистого эндотелия [10, 11].

\section{Обсуждение}

В настоящее время насчитывают до 50 нозологических фоорм, относящихся к группе васкулитов кожи. Значительная часть этих нозологий имеет между собой большое клиническое и патоморфологическое сходство. Единой общепринятой классификации васкулитов кожи нет, что связано с недостаточной изученностью этиологии, патогенеза и вариабельности клинического течения [12].

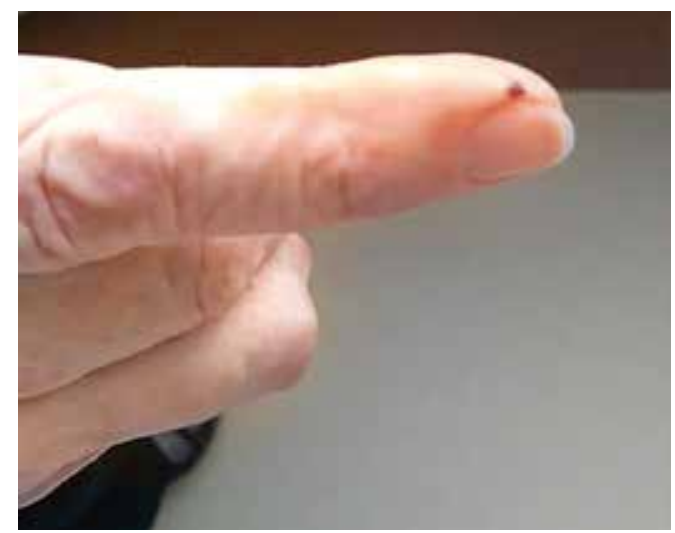

Рис. 3. Геморрагическое пятно в области ногтевой фаланги кисти Fig. 3. Hemorrhagic spot in the area of the nail phalanx of the hand

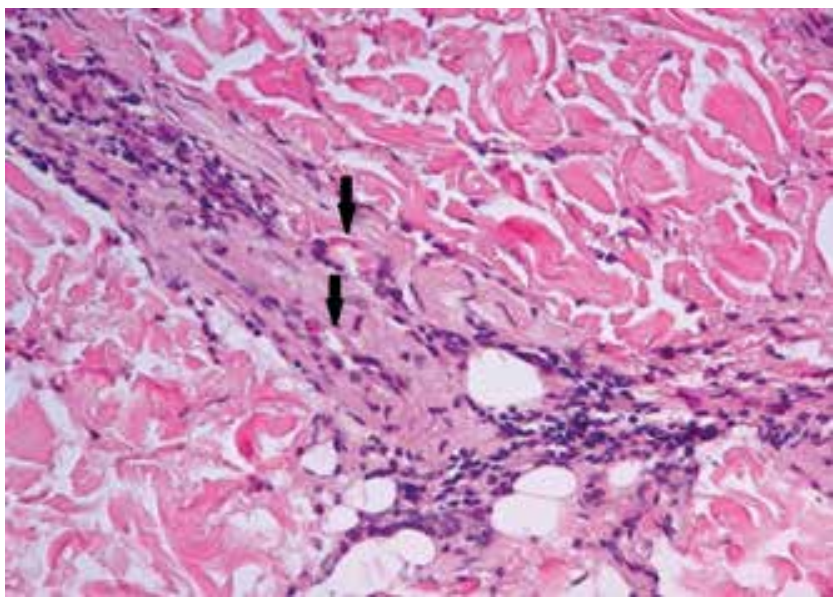

Рис. 4. Набухание и некроз стенок сосудов микроциркуляторного русла, окраска гематоксилином и эозином, $\times 200$

Fig. 4. Swelling and necrosis of the vessels of the microvasculature. Hematoxylin and eosin stain, $\times 200$

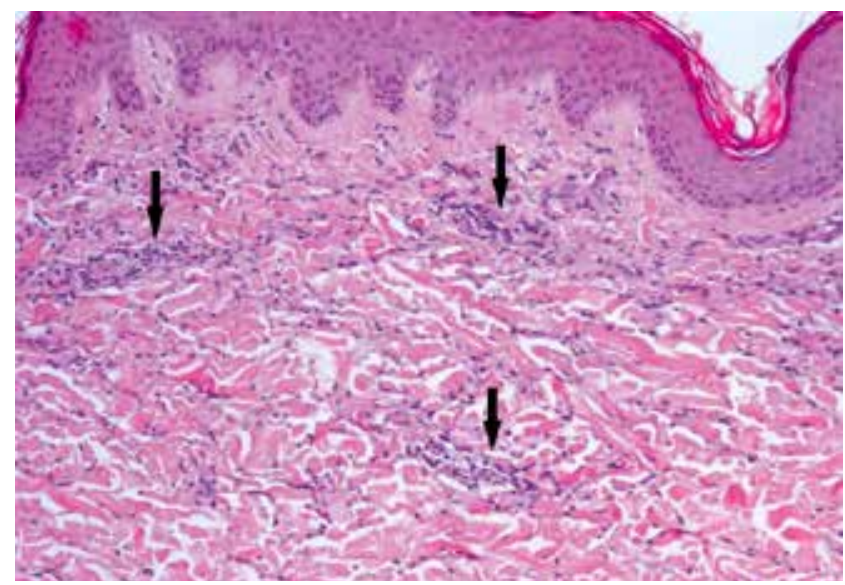

Рис. 5. Отек и инфильтрация лимфоцитами и гистиоцитами периваскулярных пространств и дермы, окраска гематоксилином и эозином, ×100

Fig. 5 . Swelling and infiltration by lymphocytes and histiocytes of the perivascular spaces and dermis. Hematoxylin and eosin stain, $\times 100$ 
Таблица. Нежелательные реакции у пациентов, получавших и-ФН0- $\alpha$, у которых позже проявились кожные васкулиты

Table. Adverse reactions in patients receiving i-TNF- $\alpha$ who later developed cutaneous vasculitis

\begin{tabular}{|c|c|c|c|c|}
\hline Авторы & $\begin{array}{l}\text { Количество } \\
\text { наблюдений }\end{array}$ & Диагноз & Препарат & Кожные проявления \\
\hline Olayemi Sokumbi и соавт. [15] & 8 & $\begin{array}{c}\text { Ревматоидный артрит (50\%), } \\
\text { болезнь Крона, язвенный } \\
\text { колит }\end{array}$ & $\begin{array}{c}\text { Инсрликсимаб }(63 \%), \\
\text { этанерцепт }(25 \%), \\
\text { адалимумаб }\end{array}$ & $\begin{array}{c}\text { Наиболее частым поражением кожи } \\
\text { были пурпура, изъязвления, пузыри } \\
\text { и эритематозные пятна. Биопсия: } \\
\text { лейкоцитокластический васкулит }\end{array}$ \\
\hline $\begin{array}{l}\text { Bernadette Saint Marcoux } \\
\text { и соавт. [16] }\end{array}$ & 39 & $\begin{array}{c}\text { Ревматоидный артрит (87\%), } \\
\text { ювенильный идиопатический } \\
\text { артрит, псориатический } \\
\text { артрит, псориаз, } \\
\text { анкилозирующий спондилит }\end{array}$ & $\begin{array}{c}\text { Этанерцепт (54\%), } \\
\text { инфрликсимаб, } \\
\text { адалимумаб }\end{array}$ & $\begin{array}{c}\text { Гистология (30 биопсий у } 27 \text { пациентов) } \\
\text { показала ненекротический васкулит } \\
\text { у } 12 \text { пациентов (31\%), некротический } \\
\text { васкулит у } 7 \text { (18\%) }\end{array}$ \\
\hline P.H. Brion и соавт. [17] & 1 & Ревматоидный артрит & Этанерцепт & $\begin{array}{l}\text { Пурпурные поражения на нижних } \\
\text { конечностях, ягодицах (биопсия: } \\
\text { некротизирующий васкулит) }\end{array}$ \\
\hline N.A. Galaria и соавт. [8] & 1 & Ревматоидный артрит & Этанерцепт & $\begin{array}{c}\text { Пурпурные папулы на туловище } \\
\text { и конечностях (биопсия: } \\
\text { лейкоцитокластический васкулит) }\end{array}$ \\
\hline M.E. McCain и соавт. [18] & 1 & Ревматоидный артрит & $\begin{array}{c}\text { Этанерцепт/ } \\
\text { инфрликсимаб }\end{array}$ & $\begin{array}{l}\text { Эритематозные папулы и узелки на } \\
\text { туловище и конечности (биопсия: } \\
\text { лейкоцитокластический васкулит) }\end{array}$ \\
\hline K. Fujikawa и соавт. [19] & 3 & Ревматоидный артрит & $\begin{array}{c}1 \text { случай - } \\
\text { этанерцепт } \\
2 \text { случая - } \\
\text { инфлликсимаб }\end{array}$ & $\begin{array}{c}2 \text { случая - лейкоцитокластический } \\
\text { васкулит } \\
1 \text { случай — спонтанное разрешение } \\
\text { кожного процесса }\end{array}$ \\
\hline M. Ramos-Casals и соавт. [20] & 113 & $\begin{array}{c}\text { Ревматоидный артрит, } \\
\text { псориатический } \\
\text { артрит, болезнь Крона, } \\
\text { анкилозирующий спондилит }\end{array}$ & $\begin{array}{l}\text { ЭТН, инфрликсимаб, } \\
\text { адалимумаб }\end{array}$ & 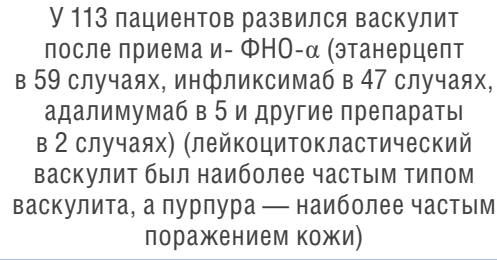 \\
\hline Seung-Bae Park и соавт. [21] & 1 & Псориаз & Этанерцепт & $\begin{array}{c}\text { Множественные болезненные } \\
\text { эритематозные узелки с коркой } \\
\text { в центре. Биопсия: узловатый васкулит } \\
\text { Монтгомери }\end{array}$ \\
\hline
\end{tabular}

В Российской Федерации используют классификацию кожных васкулитов по О.Л. Иванову и классификацию всех васкулитов (системных и кожных) по результатам международного консенсуса в 2012 г. [9, 12, 13].

По международной классификации [13] данный тип васкулита относится к васкулитам, ассоциированным с системными заболеваниями - ревматоидным артритом, или к лекарственно-индуцированным васкулитам - иммунокомплексным, либо АНЦА-ассоциированным (что было исключено при обследовании данной пациентки) кожным васкулитам (васкулит с поражением сосудов единственного органа).

Клинически заболевание проявляется множественными плотными дермальными и гиподермальными элементами в виде узлов застойно-бурой окраски на фоне геморрагических и гиперемических пятен, папул и узлов. Большая часть узелковых эффрлоресценций изъязвляется с некротизацией и образованием язвенных очагов. При снятии струпа обнажаются небольшие округлые поверхностные язвочки, а после разрешения папул остаются мелкие «штампованные» рубчики. Данные изменения наблюдались и у нашей пациентки. Высыпания располагаются симметрично с преоблада- ющим поражением разгибательных поверхностей верхних и нижних конечностей, иногда распространяясь на туловище и половые органы.

По данным современной литературы описано несколько основных гистологических типов васкулита: некротизирующий или гранулематозный с различным количеством гигантских клеток, со смешанным клеточным составом, преобладанием нейтрофилов, наличием эозинофилов, лейкоцитокластический, лимфроцитарный, лимфоплазмоцитарный васкулит, склерозирующий фриброз со скудным инфильтратом. Для определения типа поражения необходимо выявить особые признаки в виде одновременного наличия острых и затухающих сосудистых изменений, нормальных и пораженных сосудов, аневризм, микроаневризм, внесосудистых некротизирующих гранулем [14]. Проведение прямой РИФ для определения состава депозитов ( $\lg \mathrm{A} / \mathrm{lgM} / \operatorname{lgG}$ и т. д) у данной пациентки технически было невозможно, однако системность процесса была исключена.

Учитывая то, что пациентка длительное время находилась на терапии ГИБП, проводился диффреренциальный диагноз высыпаний на коже с туберкулезом кожи. Данной патологии выявлено не было. 
Учитывая клинические признаки кожного васкулита у пациентки, возникшие на фоне лечения этанерцептом, следует отметить, что нежелательные реакции в виде данной патологии в литературе описаны в единичных случаях и чаще всего встречаются как раз на фоне лечения этим препаратом (см. таблицу).

Считается, что и-ФНО- $\alpha$ агенты неэфффективны при наличии васкулита у больных ревматоидным артритом, кроме того, они могут быть причиной развития лекарственного васкулита [15-17, 22]. В случаях появления кожного васкулита на фоне лечения и-ФНО- $\alpha$ трудно диффференцировать ревматоидный васкулит и лекарственную реакцию [16]. При развитии васкулита после начала лечения и-ФНО- $\alpha$ и улучшения проявлений васкулита после отмены терапии, а также рецидива симптомов при повторной инициации и-ФНО- $\alpha$ можно расценивать васкулит как реакцию на лекарство. Иммунные комплексы, содержащие препарат, могут откладываться на стенках мелких сосудов и индуцировать активацию локального комплемента. Может играть роль дисбаланс цитокинов, вызванный ингибированием ФНО- $\alpha$, переключение с Th1 на Th2-тип иммунного ответа, что может активировать выработку антител.

\section{Заключение}

Таким образом, у нашей пациентки был диагностирован лекарственно-индуцированный васкулит кожи, развившийся на фоне лечения этанерцептом, что потребовало отмены лечения данным препаратом, после чего симптомы кожного васкулита регрессировали. С учетом основного диагноза, ревматоидного артрита, серопозитивного, с системными проявлениями (ревматоидные узелки, сухой кератоконъюнктивит), для дальнейшей терапии был выбран ритуксимаб. Признаки лекарственного васкулита при дальнейшем наблюдении не возникали.

Итак, несмотря на довольно большой арсенал препаратов для лечения ревматоидного артрита, у ряда больных возникают сложности в подборе терапии. Помимо неэффрективности лечения, наличия противопоказаний для назначения того или иного препарата у ряда больных развиваются разнообразные побочные реакции, в том числе неожиданные, парадоксальные, которые требуют порой привлечения специалистов различных специальностей для разрешения этих проблем, в том числе дерматовенерологов.

\section{Литература/References}

1. Smolen JS, Aletaha D, Mclnnes IB. Rheumatoid arthritis. Lancet. 2016:388(10055):2023-2038. doi: 10.1016/S0140-6736(16)30173-8

2. Barbieri MA, Cicala G, Cutroneo PM, Gerratana E, Palleria C, De Sarro C, et al. Safety Profile of Biologics Used in Rheumatology: An Italian Prospective Pharmacovigilance Study. J Clin Med. 2020;9(4):1227. doi: $10.3390 / \mathrm{jcm} 9041227$

3. Hernández MV, Sanmartí R, Cañete JD. The safety of tumor necrosis factor-alpha inhibitors in the treatment of rheumatoid arthritis. Expert Opin Drug Saf. 2016;15(5):613-624. doi: 10.1517/14740338.2016.1160054

4. Burmester GR, Mease P, Dijkmans BA, Gordon K, Lovell D, Panaccione $\mathrm{R}$, et al. Adalimumab safety and mortality rates from global clinical trials of six immune-mediated inflammatory diseases. Ann Rheum Dis. 2009;68(12):1863-1869. doi: 10.1136/ard.2008.102103

5. Widdifield J, Bernatsky S, Paterson JM, Gunraj N, Thorne JC, Pope J, et al. Serious infections in a population-based cohort of 86,039 seniors with rheumatoid arthritis. Arthritis Care Res (Hoboken). 2013;65(3):353-361. doi: 10.1002/acr.21812

6. Joyau C, Veyrac G, Dixneuf $V$, Jolliet P. Anti-tumour necrosis factor alpha therapy and increased risk of de novo psoriasis: is it really a paradoxical side effect? ClinExpRheumatol. 2012;30(5):700--706.

7. Mohler KM, Torrance DS, Smith CA, Goodwin RG, Stremler KE, Fung VP, et al. Soluble tumor necrosis factor (TNF) receptors are effective therapeutic agents in lethal endotoxemia and function simultaneously as both TNF carriers and TNF antagonists. J Immunol. 1993;151(3):1548-1561.

8. Galaria NA, Werth VP, Schumacher HR. Leukocytoclastic vasculitis due to etanercept. JRheumatol. 2000;27(8):2041-2044.

9. Федеральные клинические рекомендации по ведению больных васкулитами, ограниченными кожей. Российское общество дерматовенерологов и косметологов. 2020. [Federalnie klinicheskie rekomendacii ро vedeniyu bolnih vaskulitami, ogranichennimi kozhej. Rossijskoe obshestvo dermatovenerologov i kosmetologov. 2020 (In Russ.)]

10. Хайрутдинов В.Р., Белоусова И.Э., Самцов А.В. Васкулиты кожи: классификация, диагностика и дифференциальная диагности- ка (часть 2). Вестник дерматологии и венерологии. 2020;97(2):14-23. [Hajrutdinov VR, Belousova IJe, Samtsov AV. Vaskulity kozhi: klassifikacija, diagnostika i differencial'naja diagnostika (chast' 2). Vestnik dermatologii i venerologii. 2020;97(2):14--23 (In Russ.)]. doi: 10.25208/vdv1118

11. Хайрутдинов В.Р., Белоусова И.Э., Самцов А.В. Васкулиты кожи: классификация, диагностика и дифференциальная диагностика (часть 1). Вестник дерматологии и венерологии. 2020;96(1):18-27. [Hajrutdinov VR, Belousova IJe, Samtsov AV. Vaskulity kozhi: klassifikacija, diagnostika i differencial'naja diagnostika (chast' 1). Vestnik dermatologii i venerologii. 2020;96(1)18-27 (In Russ.)] doi: 10.25208/vdv548-2020-96-1-18-27

12. Иванов 0.Л. Современная классисикация и клиническое течение ангиитов (васкулитов) кожи. РМЖ. 1997;(11)3. [Ivanov OL. Sovremennaya klassificatsiya i klinicheskoe techenie angiitov (vaskulitov). RMG. 1997;(11):3 (In Russ).]

13. Sunderkötter $\mathrm{CH}$, Zelger $\mathrm{B}$, Chen KR, Requena L, Piette W, Carlson JA, et al. Nomenclature of Cutaneous Vasculitis: Dermatologic Addendum to the 2012 Revised International Chapel Hill Consensus Conference Nomenclature of Vasculitides. Arthritis Rheumatol. 2018;70(2):171-184. doi: 10.1002/art.40375

14. Morita TCAB, Criado PR, Criado RFJ, Trés GFS, Sotto MN. Update on vasculitis: overview and relevant dermatological aspects for the clinical and histopathological diagnosis - Part II. An Bras Dermatol. 2020;95(4):493-507. doi: 10.1016/j.abd.2020.04.004

15. Sokumbi O, Wetter DA, Makol A, Warrington KJ. Vasculitis associated with tumor necrosis factor- $\alpha$ inhibitors. Mayo Clin Proc. 2012;87(8):739-745. doi: 10.1016/j.mayocp.2012.04.011

16. Saint Marcoux B, De Bandt M; CRI (Club Rhumatismes et Inflammation). Vasculitides induced by TNFalpha antagonists: a study in 39 patients in France. Joint Bone Spine. 2006;73(6):710-713. doi: 10.1016/j.jbspin.2006.02.010

17. Brion PH, Mittal-Henkle A, Kalunian KC. Autoimmune skin rashes associated with etanercept for rheumatoid arthritis. Ann Intern Med. 1999;131(8):634. doi: 10.7326/0003-4819-131-8-199910190-00031 
18. McCain ME, Quinet RJ, Davis WE. Etanercept and infliximab associated with cutaneous vasculitis. Rheumatology (Oxford). 2002;41(1):116-117. doi: 10.1093/rheumatology/41.1.116

19. Fujikawa K, Kawakami A, Hayashi T, Iwamoto N, Kawashiri SY, Aramaki T, et al. Cutaneous vasculitis induced by TNF inhibitors: a report of three cases. Mod Rheumatol. 2010;20(1):86-89.

doi: 10.1007/s10165-009-0232-7

20. Ramos-Casals M, Brito-Zerón P, Muñoz S, Soria N, Galiana D, Bertolaccini $L$, et al. Autoimmune diseases induced by TNF-targeted therapies: analysis of 233 cases. Medicine (Baltimore). 2007;86(4):242251. doi: 10.1097/MD.0b013e3181441a68.

21. Park SB, Chang IK, Im M, Lee Y, Kim CD, Seo YJ, et al. Nodular Vasculitis That Developed during Etanercept (Enbrel) Treatment in a Patient with Psoriasis. Ann Dermatol. 2015;27(5):605-607.

doi: $10.5021 /$ ad.2015.27.5.605

22. Grau RG. Drug-Induced Vasculitis: New Insights and a Changing Lineup of Suspects. CurrRheumatol Rep. 2015;17(12):71. doi: 10.1007/s11926-015-0545-9

Участие авторов: все авторы несут ответственность за содержание и целостность всей статьи.

Концепция и дизайн исследования - М.Н. Чамурлиева, Ю.Л. Корсакова; сбор и обработка материала - М.Н. Чамурлиева, Ю.Л. Корсакова, Раденска-Лоповок С.Г; написание текста - М.Н. Чамурлиева, Ю.Л. Корсакова; редактирование - Т.В. Коротаева.

Authors' participation: all authors: approval of the final version of the article, responsibility for the integrity of all parts of the article.

Contribution: concept and design of the study - Maria N. Chamurlieva, Yulia L. Korsakova; collection and processing of material - Maria N. Chamurlieva, Yulia L. Korsakova, Stefka G. Radenska-Lopovok. Text writing — Maria N. Chamurlieva, Yulia L. Korsakova; editing — Tatiana V. Korotaeva.

\section{Информация об авторах}

*Чамурлиева Мария Нугзаревна - к.м.Н., научный сотрудник; адрес: Россия, Москва, Каширское шоссе, д. 34А; ORCID iD: https://orcid.org/0000-0001-5987-4413; eLibrary SPIN: 2313-4665; e-mail: mchamurlieva@mail.ru

Корсакова Юлия Леонидовна — к.м.н., старший научный сотрудник, ORCID iD: https://orcid.org/0000-0001-5968-2403; eLibrary SPIN: 6093-6060; e-mail: yulkorsakova@bk.ru

Раденска-Лоповок Стефка Господиновна - д.м.H., профресcop; ORCID iD: https://orcid.org/0000-0002-4669-260X; eLibrary SPIN: 3805-7380; e-mail: radenska@mail.ru

Коротаева Татьяна Викторовна - д.м.н., ведущий научный сотрудник; ORCID iD: https://orcid.org/0000-0003-0579-1131; eLibrary SPIN: 9855-5954; e-mail: tatianakorotaeva@googlemail.com

\section{Information about the authors}

*Maria N. Chamurlieva - MD, Cand. Sci. (Med.), research associate; address: 34A, Kashirskoe shosse, 115522, Moscow, Russia; ORCID iD: https://orcid.org/0000-0001-5987-4413; eLibrary SPIN: 2313-4665; e-mail: mchamurlieva@mail.ru

Yulia L. Korsakova — MD, Cand. Sci. (Med.), senior research associate; ORCID iD: https://orcid.org/0000-0001-5968-2403; eLibrary SPIN: 6093-6060; e-mail: yulkorsakova@bk.ru

Stefka G. Radenska-Lopovok — MD, Dr. Sci. (Med.), Professor; ORCID iD: https://orcid.org/0000-0002-4669-260X; eLibrary SPIN: 3805-7380; e-mail: radenska@mail.ru

Tatiana V. Korotaeva - Dr. Sci. (Med.), leading researcher; ORCID iD: https://orcid.org/0000-0003-0579-1131; eLibrary SPIN: 9855-5954; e-mail: tatianakorotaeva@googlemail.com

Статья поступила в редакцию: 15.04 .2021

Принята к публикации: 22.07.2021

Дата публикации: 15.08.2021
Submitted: 15.04 .2021

Accepted: 22.07.2021

Published: 15.08 .2021 